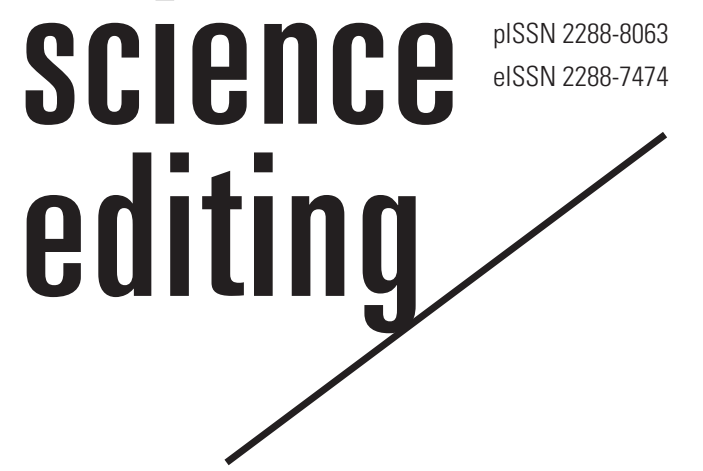

\title{
The 30-year publication history of Asian- Australasian Journal of Animal Sciences
}

\author{
Jong Kyu Ha', Cheol Heui Yun²
}

${ }^{1}$ Asian-Australasian Association of Animal Production Societies, Seoul; ${ }^{2}$ Department of Agricultural Biotechnology, College of Agriculture and Life Sciences, Seoul National University, Seoul, Korea

\begin{abstract}
Asian-Australasian Journal of Animal Sciences (AJAS) is the official journal of the AsianAustralasian Association of Animal Production Societies and was founded in 1988 in Korea. The journal was created to serve the animal industry and academia in the Asian-Australasian region through the efficient publication and distribution of scientific information on animal sciences. At the beginning, there was neither a real need expressed by member countries nor a firm belief in the success of such publication activity in Asia. However, a few dedicated individuals, led by Prof. In K. Han, the first editor-in-chief, were able to turn AJAS into one of the most respected global journals in animal sciences. Over the last three decades, AJAS has achieved notable development in the quantity and quality of the articles and their publication process. AJAS initially published four issues per year; this number grew to six issues in 1995-1998, eight issues in 1999, and 12 issues from 2000 onward. Overall, the journal has published more than 5,700 articles. Total citation frequency in 1997, when AJAS was first indexed by SCIE, was lower than 100, but by 2017, it was more than 4,000. Similar improvement was seen in the two-year impact factor, which was 0.094 in 1997 and rose to 1.243 by 2017 . This article aims to introduce the development of the AJAS editorial system, manuscript submission, publication activities, and citation frequency. Additionally, a special development, called the AJAS 2020 program, is introduced as a reference for other journals.
\end{abstract}

Keywords

Asian-Australasian Journal of Animal Sciences; Editorial system; History

Received: December 26, 2018

Accepted: January 4, 2019

Correspondence to Jong Kyu $\mathrm{Ha}$ jongha@snu.ac.kr

ORCID

Jong Kyu Ha

https://orcid.org/0000-0001-8783-4777

Cheol Heui Yun

https://orcid.org/0000-0002-0041-2887

\section{Introduction}

The Asian-Australasian Association of Animal Production Societies (AAAP), also known as 'Triple AP, now has 38 years of history behind it and has become one of the largest global academic organizations in the area of animal sciences. The AAAP was founded in Kuala Lumpur in 1980, and to honor its formation, the First AAAP Animal Science Congress was held at the campus of 
Universiti Putra Malaysia, Malaysia, September 2-5, 1980 [1].

Originally, the plan to create an Association of Animal Production Societies to represent the countries in Asia and the Pacific Rim was started in 1977 during Dr. Syed Jaladudin's tenure as the president of the Malaysian Society of Animal Production. After a few years' discussion, it was agreed that animal scientists in Asia should meet regularly to exchange ideas and discuss common problems. The Malaysian Society of Animal Production organized the First AAAP Animal Science Congress, which was a major step toward the founding of the AAAP. Dr. Jalaludin was elected the first president of the society, which had eight charter members (Australia, Indonesia, Japan, Korea, Malaysia, New Zealand, Philippines, and Thailand). The council members elected for the newly created international association, AAAP, were Dr. I. M. Nitis (Indonesia), Dr. V. G. Arganosa (Philippines), Dr. N. Tulloh (Australia), Dr. C. Chantalakhana (Thailand), Dr. Y. Yamada (Japan), Dr. In K. Han (Korea), Dr. M. Mahyuddin Dahan (Malaysia), Dr. C. Devendra (Malaysia), and Prof. A. R. Sykes (New Zealand) $[2,3]$.

The AAAP's main activities are holding the biannual AAAP Animal Science Congress and managing the publication of Asian-Australasian Journal of Animal Sciences (AJAS), its official journal. Thus far, 18 AAAP Animal Science Congresses have been held in 11 different member countries, serving as the regional platform for animal scientists in Asia to exchange their ideas and opinions, and to present current advances in animal sciences and technology.

\section{AJAS: Official Journal of the AAAP}

Although the statutes of the AAAP called for the publication of an official journal, it did not materialize until eight years after the foundation of the association. Following the Third AAAP Animal Science Congress held in Seoul, Korea, May $6-10,1985$, a proposal to publish an official journal of the AAAP was submitted to the fourth Council Meeting of the AAAP by Professors Dong A. Kim (Korea), In K. Han (Korea), Syed Jalaludin (Malaysia), and Charan Chantalakahna (Thailand). In 1987, the proposal was reconfirmed by the fifth Council Meeting of the AAAP in Hamilton, New Zealand. There Prof. In K. Han was appointed as the founding editorin-chief, and Professors D. Minson (Australia) and R. Kawashima (Japan) were appointed as associate editors of the AJAS. After about one year of preparation, the first issue (vol. 1, no. 1) of the AJAS was published in March 1988 at the Suwon campus of Seoul National University [3].

AJAS was established with the mission to serve the animal industry and academia in AAAP regions through the efficient publication and distribution of scientific information on ani- mal sciences and technology. It was, to the best of our knowledge, the first English-language journal of an international scope in Asia to cover this field. Thus, it made a tremendous contribution to the development of animal sciences in the AAAP region. During the first phase (1988-1994), AJAS published four issues per year; the number grew to six issues in 1995-1998, eight issues in 1999, and 12 issues from 2000 onward. This growth was possible thanks in part to increasing research activities in many Asian countries over the years.

\section{Editorial System Development}

\section{Editorial members}

In its 30-year history, the AJAS has had three editors-in-chief. Prof. In K. Han (Fig. 1A), the founding editor-in-chief, must be recognized for his tremendous contributions to the development of the AJAS. During his tenures as editor-in-chief (1988-1994, 1998-2001), Prof. Han nurtured AJAS, both in quantity and in quality, from its outset until 2001, when he stepped down to take a still more important position: president of the Korean Academy of Science and Technology. Prof. Dong A. Kim (Fig. 1B), a professor at Seoul National University, ran AJAS successfully for four years during the absence of Prof. In K. Han, who devoted himself to the organization of the Eighth World Conference on Animal Production. The third editor-in-chief, Prof. Jong K. Ha (Fig. 1C), took over operation of AJAS starting in 2001 after serving the journal as editorial board member, business manager, and assistant editor. In addition to the three editors-in-chief, numerous editors, editorial board members, reviewers, and editorial staff have also made outstanding contributions over the last three decades to the development of AJAS.

In 1988, when the journal was created, the editorial structure was relatively simple. The initial editorial board consisted of an editor-in-chief, two associate editors, and 20 editorial members, most of whom were invited from AAAP member countries [3]. The 2017 list shows that the board has grown into a much larger and more international team from a wider range of disciplines. As of 2018, we have one editor-in-chief, one deputy editor-in-chief, 24 associate editors, and 101 editorial members from 26 countries ( 34 from Korea, 14 from China, nine from Japan, six from the United States, four from Australia, four from Taiwan, four from Thailand, three from India, two from Canada, two from Pakistan, two from Indonesia, two from New Zealand, and one each from 13 other countries). Members are invited for an initial three-year term with the possibility of extension. Due to the complexity of editorial work in recent years, editors with special functions are also invited, such as English editor, statistical editor, managing editor, and manuscript editor. 

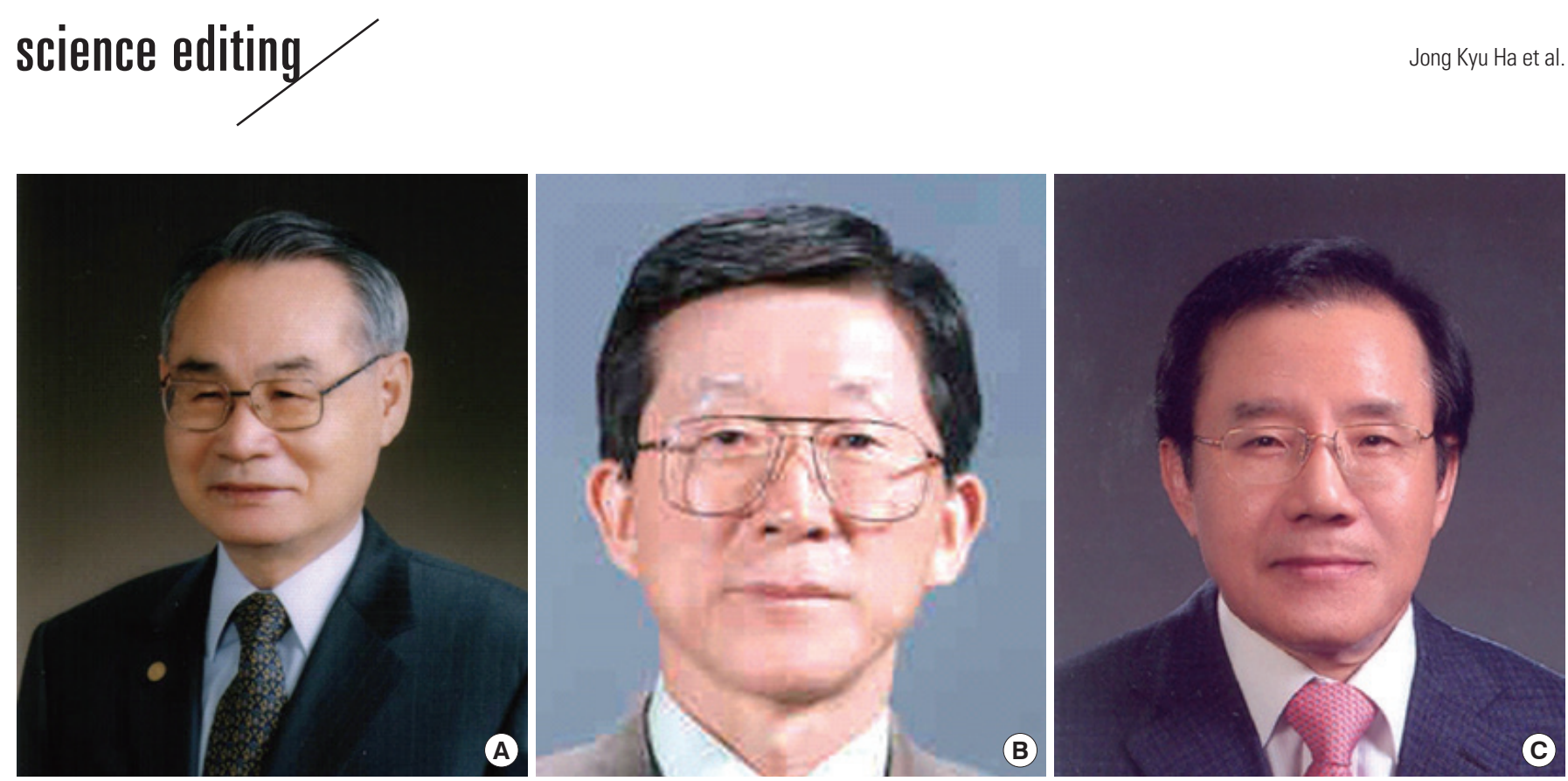

Fig. 1. Professors (A) In K. Han (the founding editor-in-chief; 1988-1994, 1998-2001), (B) Dong A. Kim (second editor-in-chief, 1994-1998), and (C) Jong K. Ha (third editor-in-chief, 2001 to present).

Guide for authors and review and editorial policy

The original guide for authors and the review and editorial policy was prepared by a few scientists led by Prof. In K. Han during the preparation for journal launching, and its final form was completed in January 1988 [3]. It was very simple, briefly describing a few essential items. The guide for authors mainly described a few key guidelines: formatting specifications, number of carbon copies to be submitted, manuscript components, and reference style (the Council of Biology Editors manual). The review policy described the method of review (single blind), the number of reviewers per manuscript, and the time frame for the review process. Initial editorial policy defined the procedures of manuscript handling, including review, revision, and publication and the responsibility of the editor-in-chief and editorial committee.

The original review and editorial policies were extensively improved in February 1999. Many editorial members gave input during the preparation of new policies. Of the many editorial members, Prof. Phil Thacker in Canada made great efforts in shaping the editorial policy of the AJAS during its early stages of development. A revised guide for authors provided much more detailed guidelines with easy-to-understand specifications. The guide for authors included submission of the manuscript (key elements of the manuscript and general guidelines), the structure of the manuscript (how to prepare each section, including reference citations), guideline for the preparation of tables and figures, the use of numbers and units, and an abbreviation list for frequently cited journals and terminologies.

One interesting aspect of the new policy was to set up a section-editor system for more efficient and fair manuscript handling, but the system was never fully implemented. Having the extra step of manuscript evaluation by the section editor might have provided a more reliable peer-review system. However, this was time-consuming, adding weeks and sometimes months to the process, because in those days, all manuscripts were circulated through regular post in a hard-copy form. The "Responsibilities of section editors" were presented as the following [3]:

1) Section editors are responsible to invite (collect) at least one or two quality review paper(s) in their own field from animal scientist(s) in any area of the world.

2) Section editors are also responsible for critical review of seven to eight original manuscripts per year submitted for publication in AJAS.

3) Section editors will check manuscripts returned by authors to ensure that they have been revised as suggested by editorial members, and then send the manuscript back to editor-in-chief within four weeks.

4) Section editors then will have to decide acceptance or rejection on specific manuscripts that have split decisions by two editorial members or any overdue manuscript, review process of which has not been completed by editorial members within 2 months. In this case, section editors may request a critical review from another editorial member within four weeks. Final decision should be sent to editor-in-chief in two months from the time of receiving the specific article from editor-in-chief.

5) Section editors may nominate a paper for the Purina Outstanding Research Award of the AJAS that will be pre- 


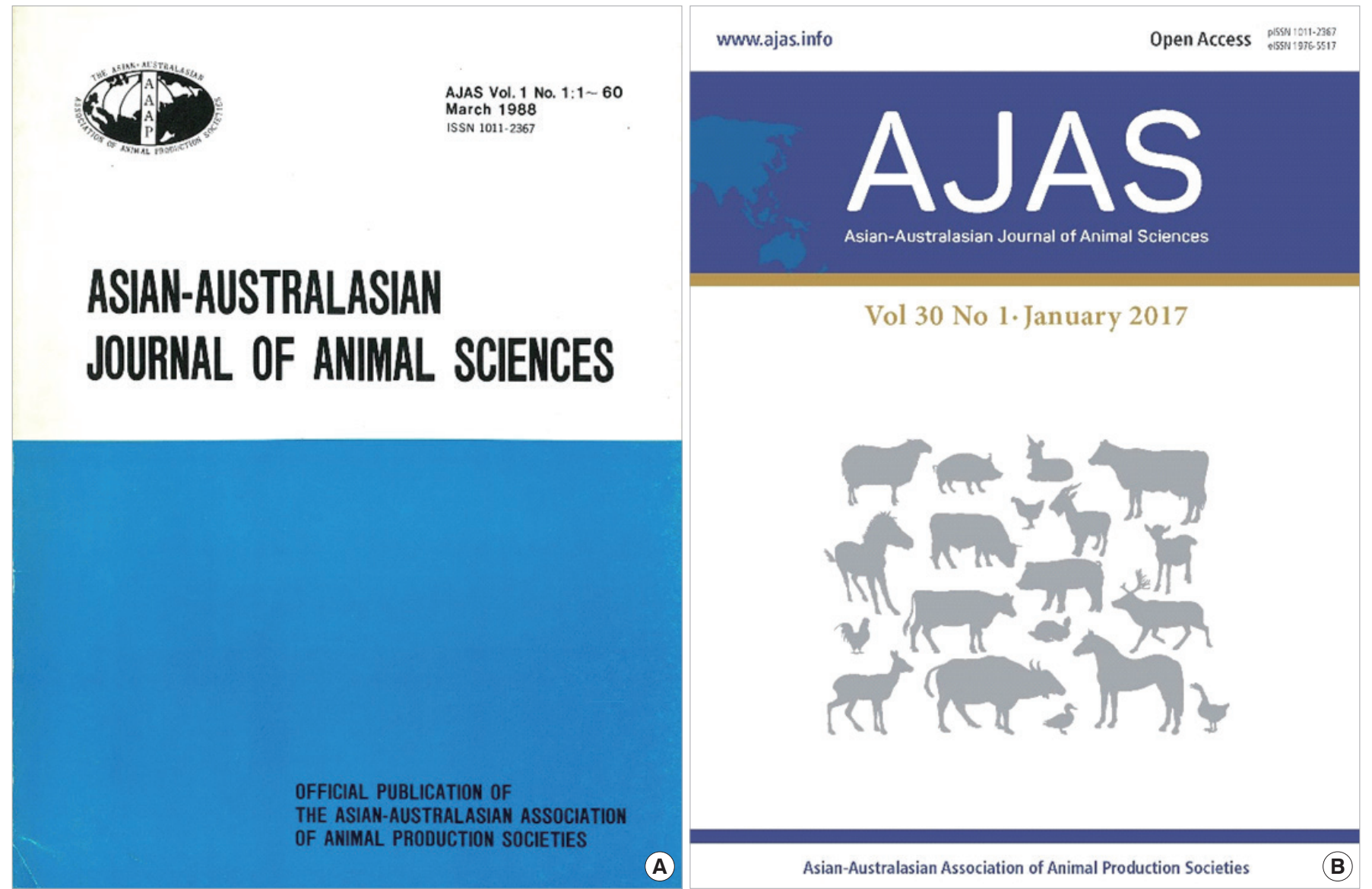

Fig. 2. The cover of Asian-Australasian Journal of Animal Sciences. (A) Before 2017 and (B) since January 2017.

sented at the opening ceremony of AAAP Animal Science Congress. The award is a cash prize of 2,000 US dollars plus a memento or plaque.

After the second revision, a few minor changes and improvements on publication policies were made. The latest and perhaps most extensive revision was made in September 2016. For the latest version, many editorial members gave considerable input, but the most important contributions were made by Prof. Sun Huh (Hallym University, Korea), Hye Min Cho (Infolumi, Korea) and Prof. Beob Gyun Kim (Konkuk University, Korea), to whom AJAS is deeply indebted. The journal-improvement project included a cover redesign, which was introduced in January 2017 (Fig. 2). The new version was prepared with attention to many aspects related to the recent international publication environment and in a way that accommodated many modern publication technologies. Major modifications include the following:

1) Aims and scope: To reflect modern developments in animal sciences, sections were rearranged, and a few new ones were introduced (animal health, animal biotech- nology, animal behavior, and welfare).

2) Open access policy: AJAS became an open access journal starting January 2014, and its declaration was included in the new version. The open access policy of AJAS was changed from /by-nc/ to /by/ in 2018.

3) Research and publication ethics: AJAS adheres to the ethical guidelines for research and publication described in the ICMJE (Guidelines on Good Publication and the International Committee of Medical Journal Editors) guidelines. Extensive ethics guidelines are announced in the latest guideline. The major parameters include authorship; originality, plagiarism, and duplicate publication; secondary publication; conflict of interest statement; care and use of animals; and the process for managing research and publication misconduct; and editorial responsibilities.

4) Submission and peer review process: More elaborated step-by-step explanations on the manuscript-handling process were provided for authors, reviewers, and the editorial staff, including the editor-in-chief. 


\section{science editing /}

5) Manuscript preparation: The basic structure and manuscript preparation guidelines of the second revised version were maintained in the 2016 version, with minor changes. Items were rearranged, expressions were improved, and a style guide was provided so authors could follow a step-by-step submission procedure. Some notable changes are: (1) The abstract style was changed from non-structured to structured. (2) The reference citation method of the Council of Biology Editors system, used since 1988, was changed to the National Library of Medicine system. All authors submitting manuscripts were asked to adhere to the new style and format starting January 2017.

\section{Manuscript Submission and Publication}

\section{System development}

Initially, like any other journal, AJAS received printed manuscripts (three copies) from authors. Two copies were sent out to two external reviewers, and one copy was kept for internal purposes. Reviewers also, of course, sent back the copy along with their comments. It took months for one round of the peer review process. The main task of the editorial staff in those days was to handle hard copies and to respond to authors and reviewers, spending hours to read and write letters. Two staff members were able to handle this process until the total number of annual submissions reached about 500. By 2004, the staff was overloaded and did not have enough time to take care of other business. AJAS, with the help of the company Aninet (Korea), developed its own manuscript-submission and handling system, which was inaugurated on January 1, 2006. This was one of the most important steps in AJAS's transition toward an online operation system. Although the system was not perfect by any means, authors, reviewers, editorial members, and staff valued the system, which saved time and money for all stakeholders in AJAS for almost nine years. Then, as the number of submissions dramatically increased, it became necessary to use a more powerful and more efficient online system. After a year's preparation, AJAS contracted with a new web hosting company, M2 Community, in September 2014.

\section{Manuscript submission}

A dramatic increase was seen in the number of submissions. They grew from 50 in 1988 to almost 1,000 annually in 2016 (Fig. 3), indicating that animal scientists consider AJAS a good journal in which to publish their work [4]. At the same time, this trend may reflect the increased research activity in the AAAP region, especially in East Asia and some developing countries, in recent years. Chinese scientists submitted 291 manuscripts (30.8\%) in 2017, while Korean scientists sub-

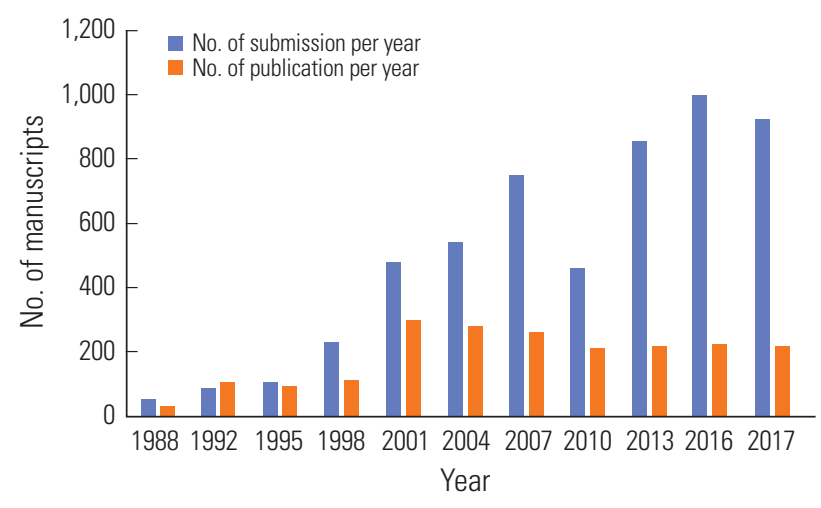

Fig. 3. Manuscript submission and publication by Asian-Australasian Journal of Animal Sciences (1988-2017).

mitted 130 manuscripts (13.8\%). Other major contributors in terms of manuscript submission to AJAS in 2017 were from Brazil (7.9\%), India (6.3\%), Iran (4.5\%), Thailand (3.7\%), Turkey (2.9\%), Indonesia (2.9\%), Pakistan (2.1\%), and South Africa (2.0\%). Japan was a major contributor until the year 2000; however, its share dropped to less than $1 \%$ of total submissions in 2017. This is likely due to Japan's success in launching many SCIE journals in recent years. Although China has also recently made remarkable advances in journal publication, not all manuscripts generated from their research activities would be accommodated.

\section{Publication activities}

As mentioned previously, AJAS initially published four issues per year (1988-1994), but 12 issues a year have been published since 2000. A total of 301 articles were published in 2001, and annual publication numbers have been maintained at around 220 articles (Fig. 3) in the last 10 years [4].

Table 1 shows the number of publications by AAAP member countries over the past 30 years. As can be seen, the majority of articles (78.4\%) came from AAAP member countries. Initially, fewer than 10 AAAP member countries published papers in AJAS, but in 2017, scientists from more than 30 different countries chose AJAS to publish their work, indicating that AJAS is now recognized as an international journal. Korean scientists published the most papers over the three decades, followed by scientists from Japan, China, India, Taiwan, and Thailand.

As AJAS has gained popularity, thanks in part to recent considerable improvements in its impact factor, publication by authors from non-AAAP regions also increased. The recent three-year statistics presented in Table 2 clearly show such a trend. Korea and China, as AAAP member countries, are the two major countries that contributed the most, but the contribution by other non-AAAP members such as the Unit- 
Table 1. Manuscripts published by Asian-Australasian Association of Animal Production Societies member countries (1988-2017)

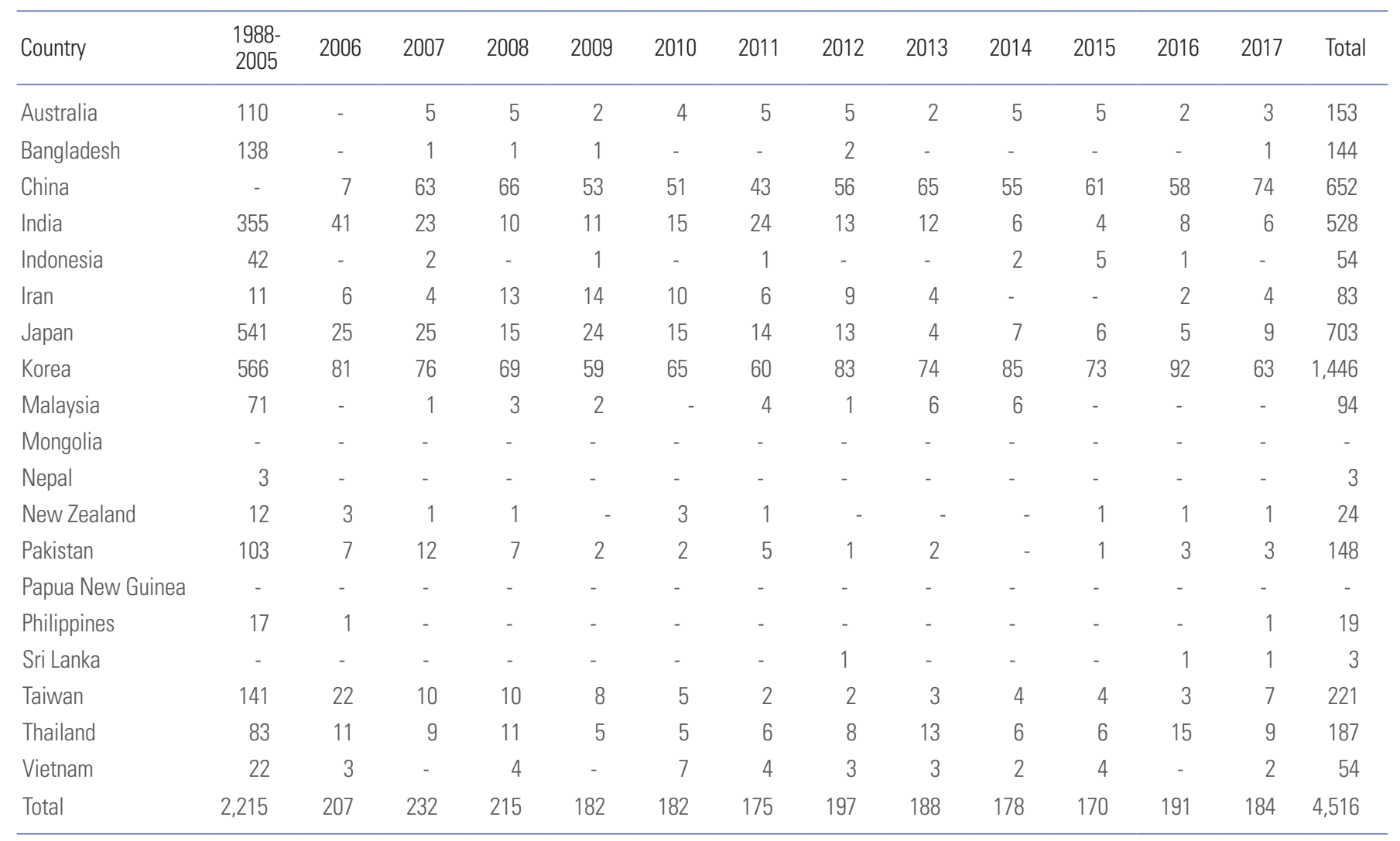

Nineteen Asian-Australasian Association of Animal Production Societies member countries: 4,516 papers (78.4\%); Non-Asian-Australasian Association of Animal Production Societies member countries: 1,244 papers (21.6\%). Published articles from 33 countries in 2017.

Table 2. Publication contributions in the most recent 3 years (2015-2017)

\begin{tabular}{lc}
\hline Country & No. of articles \\
\hline Korea & 240 \\
China & 201 \\
USA & 55 \\
Thailand & 35 \\
Japan & 31 \\
Brazil & 28 \\
India & 19 \\
Turkey & 18 \\
Australia & 15 \\
Taiwan & 15 \\
Mexico & 15 \\
Canada & 5 \\
\hline
\end{tabular}

ed States, Brazil, Turkey, Mexico, and Canada is growing.

Original research articles and reviews were the main form of AJAS publication thus far, and it is time to consider some changes. In 2018, two editorial papers covering AJAS's 30-year history [4] and a guide for experimental design and statistical analysis [5] were published. In the same year, AJAS published its first special issue: vol. 31 , no. 7 was dedicated solely to global beef production. We certainly hope these types of publications will provide more interesting and informative content to our readers. We believe that AJAS should consider a wider range of content types, so that other technical notes, short reports, or letters to the editor can be accepted by AJAS in the near future. One good approach would be to carry abstracts presented at the AAAP Animal Science Congress, which would properly facilitate the citation of presenters' work. As the official journal of the Association, AJAS needs to provide as much service as possible to member countries. Given the rapid changes in the global publication environment as well as the technology involved, it is certainly the right time to consider other types of information presentation beyond text, such as infographics, video, audio, and summary graphics, so that we can accommodate a variety of needs from the community. 


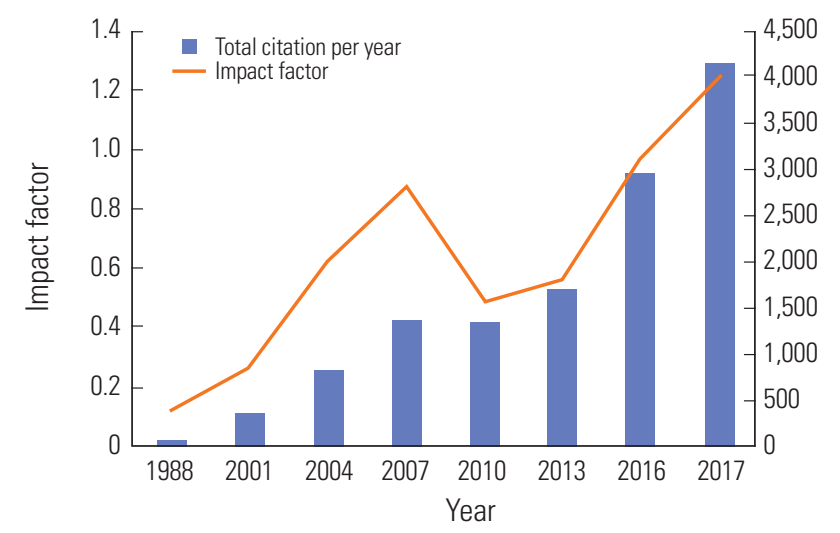

Fig. 4. Trend in total citation frequency and two-year impact factor of AsianAustralasian Journal of Animal Sciences (1998-2017).

\section{Citation Frequency}

AJAS was indexed by SCIE for the first time in 1997 and had an impact factor of 0.094; the impact factor rose to 1.243 in 2017, as shown in Fig. 4. The total number of citations in the first year was low (fewer than 100), but by 2007 it was over 4,000 -a 40 -fold increase in 20 years. Significant improvements were made during the past three years, and the trend is expected to continue in the future. Recently, added coverage by major international databases such as PMC (PubMed Central), DOAJ (Directory of Open Access Journals), and the adoption of the open-access policy are considered major contributors to the growth in citations.

Although AJAS did an excellent job in improving citation frequency in recent years, its relative ranking in the animal science area is not high enough. It stands in the upper $66 \%$ in terms of the two-year impact factor (Table 3). It is worth noting that the ranking calculated on the basis of total citations in AJAS is much better than that calculated based on impact factor-perhaps an indication that the journal's impact factor will improve in the long term.

\section{AJAS 2020 Program}

AJAS launched a seven-year improvement plan (AJAS 2020 program for 2013-2020) in 2013. As the editor-in-chief and all editorial members tried to turn AJAS into one of the top journals globally, a well-organized and systemic action plan was necessary to carry out the improvement plan. After a long discussion among the editorial members, the following AJAS 2020 program was born. It defined the mission and vision of AJAS's publication, and the goals to be achieved within seven years were established. Four key areas for journal improvement were identified: (1) journal exposure and citation frequency, (2) journal management, (3) editorial, and (4) budget.
Table 3. Asian-Australasian Journal of Animal Sciences ranking in agriculture, dairy, and animal sciences (\% position from top journal) $)^{\mathrm{a})}$

\begin{tabular}{lcccccc}
\hline & 2012 & 2013 & 2014 & 2015 & 2016 & 2017 \\
\hline IF ranking & 39 & 36 & 32 & 47 & 60 & 66 \\
$\begin{array}{l}\text { Total cites } \\
\text { ranking }\end{array}$ & 65 & 63 & 74 & 74 & 76 & 82 \\
\hline
\end{tabular}

alPercentage position compared to the top journal as $100 \%$.

\section{Outline of AJAS 2020 program}

Mission of the program was to serve the animal industry and academia in the AAAP region by the efficient publication and distribution of scientific information on animal sciences. The vision was to become a globally important and respectable journal in the area of animal sciences with sustainable structure. To achieve the vision of the program the program's goals were set for AJAS to become a top 30\% journal in animal sciences or a top $10 \%$ journal with multi-disciplinary nature covering major areas of animal sciences with $>2.0$ impact factor.

The first strategy was to increase journal exposure and citation frequency. Some of measures to be considered were: adoption of open access policy with full-text XML service, coverage by Medline/PubMed Central, creation of new sections such as laboratory animals and animal health (veterinary science) covering hot topics citable by non-livestock sectors (medical, veterinary, and/or basic sciences), invited review papers, social networking services (Facebook, Twitter, Youtube, mobile web).

Next strategy was to improve journal management. Examples of measures to taken were: to develop the system for better service to authors, subscribers, reviewers, supporters, and the general public, to upgrade journal quality and credibility by updating publishing policies and technologies, to improve journal style (cover, PDF), to upgrade homepage to international standard, and to register AJAS and/or AAAP as a foundation for more official status and fundraising.

The third area was editorial aspect. The followings were proposed: Separate editorial board and reviewer pool, Reduce editorial board to about 50 members representing AAAP and non-AAAP countries, strengthen reviewer pool and secure more reviewers for efficient and professional evaluation, upgrade reviewer qualification, adopt best reviewer of the year program, improve manuscript handling process and review system, create section-editor system to improve manuscript handling and to provide more professional and independent decisions.

Budget is also vital area for achieving goals of AJAS 2020 program. The following aspects were considered. Current sources of budget are subscriptions, reprints, page charges, ad- 
vertisements, and institutional support. Subscriptions and reprints budgets are expected to diminish, while advertisements and institutional support are uncertain. Under these conditions page charges will be the main source of funding, and a substantial increase will be inevitable in the next few years (from $30 \%$ to $50 \%$ of publication cost). It is also important to secure sustainable funding sources from the government and private sectors.

Progress of the AJAS 2020 program

Setting the goal was initially most important, but checking and evaluating the progress regularly, adjusting the program, and setting the action plan appears to be necessary. We checked the progress of each category at least once every year and discussed the results at the associate editors' meeting. Moreover, the progress was reported to both the AJAS general editorial meeting and the AAAP council meeting, which were held during the biannual AAAP Animal Science Congress.
Table 4 summarizes the progress made in major categories by the end of 2017. Most of the goals set in 2013 were already achieved by the end of 2017, with one exception: the official registration of AJAS (or AAAP). Achieving this is essential for the future development of AJAS, but it will take additional time to consider the factors involved in the method and form of legal registration. The overall assessment on the effectiveness of the AJAS 2020 program is that we have made good progress in the first five years, and one of the results is the improvement in the impact factor score and journal citation frequency in the last three years.

\section{Conclusion}

Publishing a science journal is a challenge in itself. This is especially true these days, when the world seems to be moving and changing so rapidly. Even though AJAS has done well in

Table 4. Progress of AJAS 2020 program

\begin{tabular}{|c|c|c|}
\hline Category & Target (2020) & Progress as of the end of 2017 \\
\hline \multirow{6}{*}{ Journal exposure \& citation } & Open access & joined on January 1, 2014 \\
\hline & XML service & Converted all articles from 2012 onward \\
\hline & PubMed Central & Indexed from July 2014 \\
\hline & Invited review & 19 articles since 2009 \\
\hline & SNS & Facebook open in September 2014 Mobile journal(http://ajas.info/m/) \\
\hline & DOI & Completed submission of DOI of all articles (from the 1st issue) in 2015 \\
\hline Journal management & MS handling system & A new system from October 2014 \\
\hline \multirow[t]{6}{*}{ Editorial process } & Ethics & Join Similarity Check, adopt COI, IRB from 2014 \\
\hline & Editorial structure & New system from January 2015 \\
\hline & Reviewer pool & Total 322 as of December 2017 \\
\hline & Editorial board & Total 101 as of December 2017 \\
\hline & Staff & Maintain 2 as of December 2017 \\
\hline & Training \& education & Attend several International \& domestic meetings per year \\
\hline \multirow[t]{2}{*}{ Budget sustain-ability } & Advertisement & Maintain 5 as of December 2017 \\
\hline & Page charge & Increased rate (July 2014) \\
\hline
\end{tabular}

AJAS, Asian-Australasian Journal of Animal Sciences; IF, impact factor; SNS, social network service; MS, manuscript; COI, conflict of interest; IRB, institutional review board. 


\section{science editing/}

carrying out its mission over the last 30 years, many challenges lie ahead.

Competition with journals belonging to or managed by large international publishers will be one such challenge. Special tactics that may suit a rather small and non-bundle journal such as AJAS should be developed. Currently, AJAS covers almost all areas of animal sciences. Providing specialized information (in discipline, animal species, climate, region, etc.) can be one tactic for surviving. Furthermore, today we are constantly pushed to adopt new technologies, and publishing journals is no exception. The rapid developments in information technology and the new programs created have to be adopted, and sometimes almost enforced, to keep up with other journals. Constant training and education, along with a supply of new blood to the journal-managing system, is essential.

How to increase multidirectional communication among authors, reviewers, editors, readers, and the general public is another challenge. AJAS exists to help animal scientists publish their original work, through which field practitioners in the AAAP region can obtain the information they need. Perhaps in the past, we spent too much energy considering how to increase the impact factor and forgot about the meaning of the real impact of scientific development and how it should be used. AJAS may set up some communication channels in online and/or offline gatherings during the AAAP Animal Science Congress.

Since AAAP does not have individual membership, no revenue comes from member subscriptions. Industry support is diminishing, as is public support. The identification of new funding sources will be a big challenge for the sustainable publication of AJAS.
Jong Kyu Ha et al.

\section{Conflict of Interest}

Cheol Heui Yun serves as an editor of Science Editing, but have no role in the decision to publish this article. Except for that, no potential conflict of interest relevant to this article was reported.

\section{Acknowledgments}

Special thanks are expressed to Hae J. Ahn (business manager) and Kyung S. Pyun (manuscript editor) for data compiling and analysis for this article.

\section{References}

1. Jalaludin S. Contribution of AAAP to the development of animal production in Asia and Pacific region. Paper presented at: Proceedings of the 8th AAAP Animal Science Congress; 1996 Oct 13-18, Tokyo, Japan. p. 35-41.

2. Han IK. Publication report of the Asian-Australasian Journal of Animal Sciences over its history of 15 years: a review. Asian-Australas J Anim Sci 2002;15:124-44.

3. Han IK. Quarter century history of the AAAP. Seoul: Asian-Australasian Association of Animal Production Societies and Hans' Animal Life Science Foundation; 2005.

4. Ha JK. Celebrating the 30th anniversary of the Asian-Australasian Journal of Animal Sciences. Asian-Australas J Anim Sci 2018;31:1-2. https://doi.org/10.5713/ajas.2018.0001ED

5. Seo S, Jeon S, Ha JK. Guidelines for experimental design and statistical analyses in animal studies submitted for publication in the Asian-Australasian Journal of Animal Sciences. Asian-Australas J Anim Sci 2018;31:1381-6. https:// doi.org/10.5713/ajas.18.0468 